\title{
Economics
}

\section{Profitability of Investment and Farm Level Efficiency Among Groups of Vitamin A Cassava Farmers in Oyo State Nigeria}

\author{
Ogunleye Ayodeji Sunday*, Bamire Adebayo Simeon, Awolola Olatundun \\ Department of Agricultural Economics, Obafemi Awolowo University, Ile-Ife, Nigeria \\ Email address: \\ ogunleyedeji@yahoo.co.uk (A. S. Ogunleye), asbamire@yahoo.co.uk (A. S. Bamire ), awolola.o@yahoo.com (O. Awolola) \\ ${ }^{*}$ Corresponding author
}

\section{To cite this article:}

Ogunleye Ayodeji Sunday, Bamire Adebayo Simeon, Awolola Olatundun. Profitability of Investment and Farm Level Efficiency Among Groups of Vitamin A Cassava Farmers in Oyo State Nigeria. American Journal of Environmental and Resource Economics.

Vol. 8, No. 1, 2019, pp. 14-19. doi: 10.11648/j.eco.20190801.13

Received: August 27, 2018; Accepted: September 21, 2018; Published: February 27, 2019

\begin{abstract}
Biofortified (vitamin A) cassava was developed through convectional breeding similar to most other improved varieties cultivated by Nigeria farmers. Despite its potential in addressing the increasing food demand and malnutrition in the country, lack of empirical knowledge about its yield and return on investment has been a major barrier to the uptake of this technology among farmers in Nigeria. This study examined the socio-economic characteristics of vitamin A cassava farmers; analyzed farm level efficiency and return on investment from vitamin A cassava in the study area; determined the factors affecting farm level efficiency and productivity, and examined the constraint to productivity and profitability among vitamin A cassava farmers. A multistage random sampling was used to select a total of 100 vitamin A cassava farmers in the study area. The data collected were analyzed using descriptive statistics, stochastic frontier production function (SFPF), profitability ratio and regression analysis. The results indicated that investing in vitamin A cassava as a business was very profitable. The result showed that $82 \%$ of the respondents were male, the mean age of the farmers was $53.25,49 \%$ had only primary school certificate education, $66 \%$ farmed on the land between 1-2 hectares. The result further showed that on the average, total revenue was N261511.90, the total variable cost was N87754, gross margin was N173757.9, total cost was N179828.8, and net income was N81683.05. Mean technical efficiency was $78.73 \%$. The study concluded that vitamin A cassava production in the study area was efficient and profitable. These results have implications for the design of effective advocacy strategies to attract more farmers into vitamin A cassava production in Nigeria.
\end{abstract}

Keywords: Profitability, Vitamin A Cassava, Technical Efficiency

\section{Introduction}

Biofortified cassava variety popularly known as Vitamin A cassava was developed through convectional breeding similar to most other improved varieties cultivated by Nigeria farmers [1]. The varieties that were released by the National Variety Release Committee of Nigeria are; UMUCASS 36, UMUCASS 37, and UMUCASS 38; and are recognized as IITA genotypes TMS 01/1368, TMS 01/1412, and TMS 01/1371. These were developed by the International Institute of Tropical Agriculture (IITA) in partnership with the National Root Crops Research Institute, Nigeria using traditional breeding methods in a HarvestPlus- funded project. The development and delivery of vitamin A cassava in Nigeria has been ongoing for more a decade and it is intended to complement existing national strategies in combating nutrient deficiency. Cassava is the most important staple food in Nigeria given the number of people who eat it daily and the huge amount of calories derivable. It has evolved from being a peasant's crop to cash and industrial crop. With low cost of production, vitamin A cassava varieties have a high potential to reduce poverty and malnutrition among the smallholder farm households in Nigeria. Despite the potential of vitamin A cassava in addressing the increasing food demand and malnutrition among the growing population in Nigeria, studies [2] have 
shown that one of the barriers to the uptake of new technology among the rural households is usually lack of empirical knowledge about the yield and return on investment. In this paper, we address this area by examining the socioeconomic characteristics of vitamin A cassava farmers, determining the profitability and productivity of vitamin A cassava, analyzing factors affecting its profitability, and examining the constraints to vitamin A cassava productivity and profitability with a view to enhancing its performance in the study area.

\section{Efficiency- Stochastic Frontier Analysis}

The production frontier has undergone a substantial development in recent years. The earliest works on production frontiers assumed these to be deterministic [3], [4] \& [5]. Deterministic frontiers attribute all deviations from the frontiers to inefficiency. Studies have argued that the parameters of deterministic frontiers were estimated with a mathematical programming technique (which is nonstatistical) [6] \& [7]. He also indicated that the one-sided disturbance term of the deterministic frontier explicitly assumes some particular form that violates the regularity of conditions for the application of maximum likelihood. Therefore, the estimation of deterministic frontiers is not completely straightforward. This issue has motivated other researchers to develop a probabilistic frontier [8]. However, since a probabilistic frontier is a deterministic frontier computed from a subset of the original sample using a mathematical programming technique, it remains nonstatistical, which makes hypothesis-testing impossible. Other studies [9] \& [10] attempted to address the problems associated with deterministic and probabilistic production frontiers by introducing a stochastic production frontier. The stochastic production frontier decomposes the disturbance term into measurement error and inefficiency effect. The parameters in the stochastic frontiers are estimated with the maximum likelihood approach. The present study adopts the stochastic frontier approach already developed by earlier studies [11]. The production frontier of the cassava farms can be modeled with a general stochastic frontier model:

$$
\mathrm{R}_{\mathrm{i}}=\mathrm{f}\left(\mathrm{x}_{\mathrm{ij}} ; \beta\right) \mathrm{e}^{\left(\emptyset_{\mathrm{i}}-\eta_{\mathrm{i}}\right)}, \mathrm{u}_{\mathrm{i}}=\emptyset_{\mathrm{i}}-\eta_{\mathrm{i}} \text { and } \mathrm{i}=1,2, \ldots \mathrm{J}, 2, \ldots . \mathrm{N} ; \mathrm{j}=
$$

Where $R_{i}$ denotes the output of the $i^{\text {th }}$ farm, $\left(x_{i j}\right)$ represents a $(1 \mathrm{xK})$ vector of inputs, and $\beta$ is $(\mathrm{kx} 1)$ vector of the unknown parameters to be estimated. Equation (1) is a nonlinear function that is linearized (2) by taking the natural logarithm of both sides and manipulating the relevant terms to give (2), which is a Cobb-Douglas production frontier.

$$
\ln R_{\mathrm{i}}=\alpha+\sum_{\mathrm{j}=1}^{\mathrm{J}} \beta_{\mathrm{j}} \ln \mathrm{x}_{\mathrm{ij}}+\emptyset_{\mathrm{i}}-\eta_{\mathrm{i}}, \mathrm{u}_{\mathrm{i}}=\emptyset_{\mathrm{i}}-\eta_{\mathrm{i}} \ldots
$$

Where $\emptyset_{\mathrm{i}}$ is the systematic random error that accounts for measurement error and other factors that are not under the control of the farm household, and $\eta_{\mathrm{i}}$ denotes the asymmetric non-negative random error component that measures technical inefficiency effects. The systematic random error variable is assumed to be independently and identically distributed with zero mean and variance $\sigma^{2}[12]$. The nonnegative variable, $\eta_{\mathrm{i}}$, is assumed to be independently and identically distributed truncations (at zero from below) of the $\mathrm{N}\left(0, \sigma^{2}\right)$ distributed. Moreover $\emptyset_{\mathrm{i}}$ and $\eta_{\mathrm{i}}$ are assumed to be independent of each other and also independent of the input $\mathrm{x}_{\mathrm{ij}}$. The variance parameters of the model are parameterized as in (3):

$$
\sigma^{2}=\sigma_{\emptyset}^{2}+\sigma_{\eta}^{2}, \gamma=\frac{\sigma_{\eta}^{2}}{\sigma_{\varnothing}^{2}} \text { and } o \leq \gamma \leq 1
$$

The technical efficiency of a farm, denoted by $\mathrm{TE}_{\mathrm{i}}$, can be estimated as:

$$
T E_{i}=\frac{R_{i}}{R_{i}^{*}}=\frac{f\left(x_{i} ; \beta\right) e^{\left(\phi_{i}-\eta_{i}\right)}}{f\left(x_{i} ; \beta\right) e^{\left(\phi_{i}\right)}}=e^{-i}
$$

\subsection{Profitability - Farm Budgeting Techniques}

The budgeting technique is used to analyse costs and returns to biofortified cassava production. The gross margin analysis was used to estimate the returns to pro-vitamin A. This involved gross income minus total variable costs. Net farm income $=$ total gross margin minus explicit fixed costs. Profitability is the ability of a firm to generate income that will cover all costs incurred at various levels during the production. Profitability ratios are designed to evaluate the firm's ability to generate earnings.

$$
\mathrm{GM}=\sum_{\mathrm{i}=1}^{\mathrm{n}} \mathrm{Y}_{\mathrm{i}} \mathrm{P}_{\mathrm{yi}}-\sum_{\mathrm{i}=1}^{\mathrm{n}} \sum_{\mathrm{i}=1}^{\mathrm{k}} \mathrm{PX}_{\mathrm{i}}
$$

Where $\mathrm{GM}=$ Gross Margin, $\mathrm{P}_{\mathrm{yi}}=$ Unit price of the product, $\mathrm{P}_{\mathrm{xi}}=$ Unit price of the input, $\mathrm{Y}_{\mathrm{i}}=$ Quantity of the product, $\mathrm{X}_{\mathrm{i}}=$ Quantity of the input, $\mathrm{K}=$ number of inputs and $\mathrm{n}=$ number of enterprises.

\subsubsection{Net Profit Margin (NPM)}

NPM highlights the efficiency of operation and also indicates the average spread between the operating cost and revenue. It is an indication of the total margin available to cover operating expenses and yield a profit.

$$
\mathrm{NPM}_{\mathrm{i}}=\mathrm{TR}_{\mathrm{i}}-\mathrm{TC}_{\mathrm{i}}
$$

Where $\mathrm{NPM}_{\mathrm{i}}=$ Net profit margin of firm $\mathrm{i}, \mathrm{TR}_{\mathrm{i}}=$ Total Revenue of firm $\mathrm{i}(\$)$ and $\mathrm{TC}_{\mathrm{i}}=$ Total Cost of firm $\mathrm{i}(\$)$.

\subsubsection{Return on Investment (ROI)}

An indication of the firm's profitability from current operations without regard to the interest charges accruing from the capital structure. It is calculated as:

$$
\text { ROI }_{i}=\frac{\text { Net Profit Margin }_{i}}{\text { Total Variable Cost }}
$$

\subsection{Multiple Regression Model}

Regression analysis includes any techniques for modeling and analyzing several variables, when the focus is 
on the relationship between a dependent variable and one or more independent variables. More specifically, regression analysis helps us understand how the typical value of the dependent variable changes when any one of the independent variables is varied, while the other independent variables are held fixed. However, when we are interested in the dependence of a random variable $\mathrm{Y}$, on another variable $\mathrm{X}$ which is not necessarily a random variable, an equation which relates $\mathrm{Y}$ to $\mathrm{X}$ is usually called a regression equation as expressed below

$$
\mathrm{Y}_{\mathrm{i}}=\beta_{0}+\beta_{\mathrm{i}} \mathrm{X}_{\mathrm{i}}+\mathrm{e}
$$

Where; $Y_{i}=$ Yield, $X_{i}=$ Farm households' factors, $\beta_{0}=$ Intercept, $\mathrm{B}_{\mathrm{i}}=$ Parameter to be estimated, and $\mathrm{e}=$ Error term.

\section{Methodology}

\subsection{Research Site and Sampling Procedure}

The study was carried out in Oyo State, Oyo State is an inland State in south-western Nigeria, it is bounded in the north by Kwara State, in the east by Osun State, in the south by Ogun State and in the west by Ogun State and the Republic of Benin. Oyo State was purposively selected because it was one of the four pilot states used during the introduction of biofortified cassava varieties in Nigeria in the year 2011.

\subsection{Sampling Procedure}

Multistage sampling procedure was employed; the first stage involves purposive selection involved selection of three (3) Local Government Areas (LGA) from the thirty- three LGAs where biofortified cassava production was predominance. The second stage involved proportionate random selection of farmers from each of the LGAs based on the list of cassava growers' association obtained from the relevant agencies in each LGA. Hence, the number of biofortified cassava farmers that was chosen was a function of the number of farmers available in each LGA (to size). The proportionality factor used in the selection of farmers is stated as:

$$
\mathrm{Xi}=\mathrm{n} / \mathrm{N}^{*} 10
$$

Where $\mathrm{Xi}=$ number of biofortified cassava farmers to be sampled from a LGA, $\mathrm{n}=$ number of biofortified cassava farmers in the particular LGA, $\mathrm{N}=$ sum total number of biofortified cassava farmers in the three LGAs. In all, 100 farmers were selected and interviewed for this study. The survey questionnaire captured information on the socioeconomic characteristics of the respondents, such as age, gender, household size, education, extension contact, credit access, land tenure, distance to nearest market and farming experience. It also solicited information on technical factors such as labour, seed, fertilizer, pesticides and farm size. Information on of biofortified cassava output was captured by the survey questionnaire.

\subsection{Analytical Techniques}

Data collected were analyzed using the following analytical tools: descriptive statistics, budgetary analysis, stochastic frontier analysis (SFA) and regression analysis.

\subsubsection{Budgetary Analysis}

The gross margin analysis (GMA) was carried out to determine the profitability of provitamin A cassava production in the study area. The gross margin analysis was calculated by using the formula below:

$$
\begin{gathered}
\mathrm{GMA}=\mathrm{TR}-\mathrm{TVC} \\
\mathrm{TC}=\mathrm{TFC}+\mathrm{TVC} \\
\mathrm{NPM}=\mathrm{TR}-\mathrm{TC}
\end{gathered}
$$

Where, $\mathrm{TC}=\mathrm{TFC}+\mathrm{TVC}$

$\mathrm{GM}=$ Gross Margin, $\mathrm{TR}=$ Total Revenue, $\mathrm{TC}=$ Total Cost, $\mathrm{TFC}=$ Total Fixed Cost, $\mathrm{TVC}=$ Total Variable Cost and NPM $=$ Net Profit Margin

\subsubsection{Multiple Regression Analysis}

The multiple regression analysis was used to determine factors influencing the profitability of provitamin A cassava production.

The implicit function relating to the gross margin can be expressed as:

$$
\mathrm{Z}=\mathrm{f}\left(\mathrm{X}_{\mathrm{i}}, \mathrm{U}\right)
$$

Double-log model was used for the multiple regression analysis. The explicit function is expressed as follows:

$$
\ln \mathrm{Z}=\ln \mathrm{B}_{0}+\mathrm{B}_{1} \ln \mathrm{X}_{1}+\mathrm{B}_{2} \ln \mathrm{X}_{2}+\mathrm{B}_{3} \ln \mathrm{X}_{3}+\mathrm{B}_{4} \ln \mathrm{X}_{4}+\mathrm{B} 5 \ln \mathrm{X} 5+\mathrm{U}
$$

Where: $Z=$ Net Profit, $X_{1}=$ Age in years, $X 2=$ Marital status $(1=$ married, $0=$ Others $), X 3=$ years of schooling, $\mathrm{X} 4=$ Household size in number of persons, X5 = Years of experience and $\mathrm{U}=$ error term.

\section{Results and Discussions}

\subsection{Socioeconomic Characteristics Vitamin A cassava Farmers}

The socioeconomic characteristics of the farmers as shown in table 1 indicated that the average age biofortified cassava farmers in study area was 53 years with average years of 3.5 years in the production of biofortified cassava.

Table 1. Socioeconomic characteristics of vitamin A cassava farmers

\begin{tabular}{lll}
\hline Socioeconomic Variable & Frequency & Percentage \\
\hline Age (years) & & \\
$1-14$ & 13 & 13.0 \\
$15-64$ & 66 & 66.0 \\
Above 65 & 21 & 21.0 \\
Total & 100 & 100.00 \\
Mean (Std. Dev.) & $53.25(9.76)$ & \\
Gender & & \\
Male & 82 & 82.0 \\
Female & 18 & 18.0 \\
\hline
\end{tabular}




\begin{tabular}{lll}
\hline Socioeconomic Variable & Frequency & Percentage \\
\hline Total & 100 & 100.00 \\
Household Size (\#) & & \\
Below 5 & 17 & 17.0 \\
5-10 & 58 & 58.0 \\
Above 10 & 25 & 25.0 \\
Total & 100 & 100.0 \\
Mean (Std. Dev.) & $6.2(1.8)$ & \\
Years of Education (years) & & \\
No Education & 13 & 13.0 \\
Primary Education & 49 & 49.0 \\
Secondary Education & 25 & 25.0 \\
Tertiary Education & 13 & 13.0 \\
Total & 100 & 100.0 \\
Mean (Std. Dev.) & $4.36(1.36)$ & \\
Farming Experience (years) & & \\
Below 10 & 35 & 35.0 \\
11-20 & 33 & 33.0 \\
Above 21 & 32 & 32.0 \\
Total & 100 & 100.0 \\
Mean (Std. Dev.) & $3.5(1.68)$ & \\
dMarital Status & & \\
Married & 85 & 85.0 \\
Farm Size (ha) & & \\
Below 1 & 6 & 86.0 \\
1-5 & 86 & 8.0 \\
Above 5 & 8 & 100.0 \\
Total & 100 & \\
Mean (Std. Dev.) & $2.3(0.78)$ & \\
\hline
\end{tabular}

Source: Field survey, 2015.

This implied that farmers were neither too young nor too old, and they have ample level of experience in the production the cassava since the cassava was introduced to Nigeria in 2011. The result further showed that an average household among the farmers had more than six (6) members. It is also important to note $85 \%$ of the farmers sampled were married. These have a lot of health implications on farmers' households in term of the availability of micronutrients required for healthy living. The average year of education among the farmers was 4.36 years.
This implied that the farmers would be able to understand, adopt and implement biofortified cassava innovation for optimum yield. Average farm size used for the production of the cassava among the farmers was 2.3 ha. This implied that the farmers were still getting familiar with the cassava variety and as such they were not dedicating a substantial proportion of their farmland to it compared to the already known varieties. The result also showed that both men and women farmers were involved in the production of biofortified cassava. However, the gender proportion among the farmers followed the a priori expectations.

\subsection{Farm Level Efficiency Among Vitamin A Cassava Farmers}

The maximum likelihood estimates (MLE) of the parametric stochastic frontier analysis (SFA) were shown in Table 2. The production function was estimated using stochastic frontier model. The inefficiency factors considered were age, gender, households' size, and access to planting material (stem). All the independents variables (land labour and capital (cost)) were significant at $1 \%$ and $5 \%$ level. This implied that all the production parameters played active role in determining the productivity of biofortified cassava enterprise in the study area. The average technical efficiency score among the farmers was $78.73 \%$. This implied that biofortified cassava farmers in the area were operating below the production frontier and as such, they could still increase their efficiency level by $21.27 \%$. Among the inefficiency factors considered, only access to planting material was significant $(\mathrm{p}>1)$. This implied that access to planting material was critical to the productivity of biofortified cassava farmers in the study area. The gamma diagnostics further confirmed that $97 \%$ of the inefficiency observed among the farmers was as result of the inefficiency factors considered.

Table 2. Technical Efficiency of vitamin A cassava.

Productivity

\begin{tabular}{|c|c|c|c|}
\hline Variable & Coefficient & Standard error & t- ratio \\
\hline Constant & 8.0417 & 0.1883 & $42.7134 *$ \\
\hline Land $\left(\mathrm{X}_{1}\right)$ & 0.2189 & 0.0433 & $5.0576^{*}$ \\
\hline Labour $\left(\mathrm{X}_{2}\right)$ & -0.0529 & 0.0232 & $-2.2858 * *$ \\
\hline $\operatorname{Cost}\left(\mathrm{X}_{3}\right)$ & 0.4512 & 0.0579 & $7.7968 *$ \\
\hline \multicolumn{4}{|l|}{ Inefficiency variables } \\
\hline Constant $\left(Z_{0}\right)$ & -1.7503 & 1.6636 & -1.0521 \\
\hline Gender $\left(Z_{1}\right)$ & -2.1184 & 1.6842 & -1.2578 \\
\hline Family size $\left(Z_{3}\right)$ & -0.9015 & 0.6423 & -1.4035 \\
\hline Access to Planting Material $\left(Z_{4}\right)$ & 0.2578 & 0.0679 & $3.7975^{*}$ \\
\hline \multicolumn{4}{|l|}{ Diagnostic statistics } \\
\hline Sigma squared $\left(\delta^{2}\right)$ & 2.1463 & 1.2926 & 1.6604 \\
\hline $\operatorname{Gamma}(\gamma)$ & 0.9679 & 0.0176 & 54.9495 \\
\hline Log likelihood function & 42.0505 & & \\
\hline LR Test & 22.6471 & & \\
\hline Mean Technical Efficiency & $78.73 \%$ & & \\
\hline
\end{tabular}

$*, * *, * * *$ Significant level at $1 \%, 5 \%$ and $10 \%$ respectively. Source: Field survey, 2015. 


\subsection{Profitability of Vitamin A Cassava Production}

The distribution of the various costs incurred and returns to biofortified cassava were presented in Table 3. Results showed that average total variable cost (TVC) was $\$ 69,732$. However, it is important to note that cost of planting material accounted for $13.48 \%$ of the total variable costs.

This was probably due to the fact that the cassava variety was relatively scarce because it was newly introduced to the country. Average total revenues was $\$ 261,511.90$ while the average gross margin and net profit analyses showed on the average, biofortified cassava farmers made $191,779.10$ and $\$ 176,957.70$ respectively from their cassava enterprise in the last production season. The return on investment (ROI) analysis indicated that every 1.00 spent by actors on biofortified cassava production yielded $\$ 2.09$.

Table 3. Profitability Analysis for vitamin A cassava.

\begin{tabular}{lll}
\hline Variable Cost(s) & Amount (N) & Percentage of Total Variable Cost \\
\hline Land Preparation & 33428.78 & 47.94 \\
Planting Material & 9401 & 13.48 \\
Pesticides and Herbicides & 3050 & 4.37 \\
Fertilizer & 1200 & 1.72 \\
Harvesting & 9343 & 13.40 \\
Labour Cost & 13310 & 19.09 \\
Total Variable Costs (TVC) & 69732.78 & 100.00 \\
Fixed Cost(s) & Amount(N) & Percentage of Total Fixed Cost \\
Depreciation on Land & 12885 & 86.94 \\
Sprayers & 671.4 & 4.53 \\
Wheelbarrow & 704 & 4.75 \\
Water Tank & 161 & 1.09 \\
Other Fixed Cost & 400 & 2.70 \\
Total Fixed Cost (TFC) & 14821.4 & 100.00 \\
Total Cost (TFC+TVC) (N) & 84554.18 & \\
Total Revenue (TR) (N) & 261511.90 & \\
Gross Margin (TR -TVC) (N) & 191779.1 & \\
Net Profit Margin (TR-TC) (N) & 176957.7 & \\
Return on Investment (ROI) & $209 \%$ & \\
\hline
\end{tabular}

Source: Field survey, 2015.

This implied that biofortified cassava production is profitable in the study area.

\subsection{Factors Influencing Profitability of Vitamin A Cassava Production}

Multiple regression estimates showed the level of significance of variables which were considered to be important factors influencing profitability of biofortified cassava enterprise in the study area (see Table 4). $\mathrm{R}^{2}$ indicators showed that $73.7 \%$ of the changes in the level of profit among biofortified cassava farmers were explained by the factors included in the analysis. The result of this analysis showed that household size and farm size dedicated to biofortified cassava production were the major factors that significantly influencing its probability in the study area.

Table 4. Factor Affecting the Profitability of vitamin A cassava.

\begin{tabular}{llll}
\hline Variable & Coefficient & t- value & Significant \\
\hline Gender $\left(\mathrm{X}_{1}\right)$ & -0.015 & -0.275 & 0.784 \\
Age $\left(\mathrm{X}_{2}\right)$ & -0.004 & -0.054 & 0.957 \\
Household size $\left(\mathrm{X}_{3}\right)$ & 0.185 & 2.890 & $0.005^{* *}$ \\
Farm size cultivated $\left(\mathrm{X}_{4}\right)$ & 0.856 & 14.736 & $0.002^{*}$ \\
$\mathrm{R}^{2}$ & 0.737 & & \\
Adjusted $\mathrm{R}^{2}$ & 0.726 & & \\
F- value & 66.494 & & \\
\hline
\end{tabular}

*,** mean significant level at $1 \%, 5 \%$ respectively. Source: Field survey, 2015 .

\subsection{Constrain to Vitamin A Cassava Production in the Study Area}

The constraint faced by the farmer was analyzed using descriptive analysis. Table 5, shows that about $41 \%$ of the farmers faced the challenges of poor sales of product, $33 \%$ faced low level of awareness which is applicable to the consumers and some farmers, $15 \%$ have financial problem, $6 \%$ are faced with the scarcity of stem and $2 \%$ with the deterioration of the product after one year [13].

Table 5. Constraints to vitamin A cassava among Farmers.

\begin{tabular}{lll}
\hline Constraints & Frequency & Percentage \\
\hline Access to Finance & 15 & 15.0 \\
Low Level of Awareness & 33 & 33.0 \\
Tuber Quality Diminishes after a year & 2 & 2.0 \\
Scarcity of Planting Materials (Stem) & 6 & 6.0 \\
Total & 100 & 100.00 \\
\hline
\end{tabular}

Source: Field survey, 2015.

\section{Conclusion and Recommendation}

This study examined the socio-economic characteristics; analyzed the performance of vitamin A cassava production in the study area; determined the factors affecting the performance of vitamin A cassava and examined the constraint of pro- vitamin A performance among smallholder farmers in Oyo state. Findings from the study showed an 
average age of 53 years with average years of experience of 3.5 years among vitamin A cassava farmers. Average farm size used for the production of the vitamin A cassava in the study area was 2.3 ha. The study concluded that vitamin A cassava production in the study area was efficient and profitable. Farm size, labour used and cost of production were the major determinants of farm level efficiency while access to planting materials was a significant factor contributing to inefficiency among the farmers. Household size and farm size were the major factors affecting the profitability of vitamin A cassava cassava farmers in the study area. The study therefore recommended that more farm land should be dedicated to biofortified cassava production and that access to planting materials should be improved in order to increase the profitability and farm level efficiency respectively among provitamin A cassava farmers in the study area.

\section{References}

[1] Akinwumi, A, (2011). Pro Vitamin A Cassava: a Revolution for Nutrition and Health in Nigeria Speech delivered by Dr. Akinwumi Adesina, Honourable Minister of Agriculture and Rural Development, at the launch of the Pro-Vitamin A Cassava Varieties, held at the National Root Crops Research Institute, Umudike, Abia State, pp: 1-9 Available from http://www.harvestplus.org/sites/default/files/Speech\%2016,\% 202011. 0.pdf [Accessed on 20th March, 2015]

[2] International Institute of Tropical Agriculture (IITA) (2011). Integrated cassava project in conjunction with Presidential initiative on cassava: A study on the impact of IITA's processing research on Nigeria's staple food system. [Online] Available from http:// www.iita.org/2011-iita-in-thenews;jsessionid. [Accessed Nov. 18, 2015].

[3] Farrell, M. J. (1957). The measurement of a productive efficiency. Journal of the Royal Statistical Society, Series A 120 (3): 252-281. [Online] Available from http://www.aae.wisc. edu/aae741/Ref/Farrell\%201957.pdf. [Accessed Nov. 30, 2015]
[4] Afriat, S. N. (1972). Efficiency estimation of production functions. International Economic Review 13 (3): 568-98.

[5] Battese, G. E. and Coelli, T. (1995). A model for technical inefficiency effects in a stochastic frontier production function for panel data. Empirical Economics 20 (2): 325-332.

[6] Aigner, D. Lovell, C. K. and Schmidt, P. (1977). Formulation and estimation of Stochastic frontier production function models. Journal of Econometrics 6 (1): 21- 37.

[7] Seitz, W. D. (1971). Productive efficiency in the steamelectric generating industry. Journal of Political Economy 79 (4): 878-86.

[8] Timmer, C. P. (1971). Using a probabilistic production frontier to measure technical efficiency. Journal of Political Economy 79 (2): 776-794.

[9] Gahé, Z. S. Y., Zhao, H. Belinga, T. (2016). Technical efficiency assessment using data envelopment analysis: an application to the banking sector of Côte d'Ivoire. Social and Behavioral Sciences 235 198-207.

[10] Coelli, T. J. (1995). Recent developments in frontier modeling and efficiency measurement. Australian Journal of Agricultural Economics 39(3): 219-45.

[11] José, A. M., Román, R. Miguel, G. C. \& María, S. S. (2015). Technical efficiency of thermal power units through a stochastic frontier. DYNA 82 (191), 63-68. DOI: http://dx.doi.org/10.15446/dyna.v82n191.51152.

[12] Meeusen, W. and Van den Broeck, J. (1977). Efficiency Estimation from Cobb-Douglas Production Functions with Composed Error. Int. Econ. Rev. 18: 435-44.

[13] Amao, J. O. and Awoyemi, T. T. (2008). Adoption of Improved Cassava Varieties and Its Welfare Effect on Producing Households in Osogbo ADP Zone of Osun State. Department of Agricultural Economics and Extension Ladoke Akintola University of Technology. Nigeria, 1:1-11 Available from http://www.geneconserve.pro.br/siteantigo/artigo045.pdf [Accessed on 20th January, 2015]. 